University of Nebraska - Lincoln

DigitalCommons@University of Nebraska - Lincoln

Educational Psychology Papers and

Publications

Educational Psychology, Department of

February 2000

\title{
Diversity in reasoning and rationality: Metacognitive and developmental considerations
}

David Moshman

University of Nebraska-Lincoln, dmoshman1@unl.edu

Follow this and additional works at: https://digitalcommons.unl.edu/edpsychpapers

Part of the Educational Psychology Commons

Moshman, David, "Diversity in reasoning and rationality: Metacognitive and developmental considerations" (2000). Educational Psychology Papers and Publications. 46.

https://digitalcommons.unl.edu/edpsychpapers/46

This Article is brought to you for free and open access by the Educational Psychology, Department of at DigitalCommons@University of Nebraska - Lincoln. It has been accepted for inclusion in Educational Psychology Papers and Publications by an authorized administrator of DigitalCommons@University of Nebraska - Lincoln. 
Theorists of human reasoning have typically assumed that there exists a prototypical way people think and that the goal of psychological research on reasoning is to determine what that way is. Although evidence for diversity in reasoning has long been abundant, it has typically been dismissed as artifactual or theoretically uninteresting. In an important and convincing challenge to the standard view, Stanovich \& West (S\&W) have demonstrated that, on the contrary, diversity in reasoning is genuine, substantial, systematic, and theoretically important. In this commentary, I elaborate on the nature and locus of diversity in reasoning.

Central to S\&W's analysis is a distinction between automatic heuristic processing (characteristic of what they call System 1) and explicit rule-based processing (characteristic of what they call System 2). I believe this dichotomy confounds two orthogonal distinctions. Specifically, the distinction between automatic and explicit processing is conceptually orthogonal to the distinction between heuristic and rule-based processing. Crossing automatic versus explicit with heuristic versus rule-based suggests four possible types of processing: (a) automatic heuristic processing (System 1), (b) automatic rule-based processing (not represented in the Stanovich/West analysis), (c) explicit heuristic processing (also not represented), and (d) explicit rule-based processing (System 2).

Why do S\&W collapse the two distinctions into one, and thus end up with two categories rather than four? I think it is because they focus on the literature on adult reasoning. On the tasks presented to subjects in this literature, heuristic processing tends to be automatic, whereas rule-based processing requires explicit awareness and control of one's inferences.

Research on elementary logical and mathematical inferences, however, shows that people of all ages, including preschool children, routinely make automatic inferences that are fully in accord with rules of deductive logic, probability theory, and so on (Braine \& O'Brien 1998; Hawkins et al. 1984; Huber \& Huber 1987; Scholnick \& Wing 1995). Without a steady stream of unconscious rule-based inferences, in fact, ordinary activities such as reading and conversation would be impossible.

Correspondingly, research and theory on metacognition suggest that explicit reasoning often involves the deliberate application of heuristic principles (for reviews, see Kuhn 2000; Moshman 1998; 1999). In fact, if I may momentarily construe Stanovich \& West as research subjects, the arguments they provide in their target article (and similar analyses by authors they cite) constitute clear evidence that human beings are capable of reasoning on the basis of explicit understanding about the advantages and limitations of various heuristic strategies.

Putting all this together suggests that, beginning in the preschool years, all individuals routinely make a variety of automatic inferences, both heuristic and rule-based. Over the course of development, to varying degrees, people increasingly engage in explicit reasoning. That is, they increasingly deploy and coordinate heuristic and rule-based inferences on the basis of increasing metacognitive knowledge about the nature, applicability, and justifiability of various forms of heuristic and rule-based inference (Kuhn 2000; Moshman 1994; 1998; 1999). This picture has several important implications for our understanding of human rationality that are consistent with S\&W's emphasis on diversity but go beyond their focus on individual differences.

First, without denying the importance of differences across individuals, it appears that a great deal of the diversity in human reasoning exists within individuals. From early childhood, people routinely process information, automatically and unconsciously, in accord with a variety of norms. Some of these norms are heuristic guidelines and some are strict logical or mathematical rules. Perhaps some people are more disposed toward heuristic processing and some toward rule-based processing but all people at all ages regularly engage in both. With regard to the distinction between heuristic and rule-based processing, the primary locus of diversity is within individuals. 
Second, differences across individuals appear to be largely developmental. Over the course of childhood, adolescence, and early adulthood, people increasingly - but to differing degrees - recognize that some inferences are better than others and that their conclusions and actions will be more justifiable if they constrain their inferences in accord with appropriate norms. Thus, they construct increasingly explicit knowledge about the nature and applicability of various heuristic and rule-based norms and, on the basis of this knowledge, are increasingly deliberate in their reasoning. Although automatic inferences are ubiquitous across the lifespan, there is a developmental trend toward increasingly explicit reasoning.

Finally, the present developmental picture suggests that rationality is fundamentally a matter of metacognition and only secondarily a matter of conformity to various logical or other norms. Individuals who deliberately choose to apply a particular rule, principle, framework, or metaphor on the basis of an explicit understanding of the advantages and limitations of various normative and strategic options are functioning as rational agents, even if they make mistakes in the course of their deliberations. Their rationality can be evaluated, in fact, precisely because it possible for them to make mistakes. As metacognitive agents, they can be held responsible for their inferences.

In contrast, a computer that automatically processes information in accord with its program is not a rational agent at all, even if its processing of information is fully in accord with logical or other rules (Moshman 1994). Its rationality cannot be meaningfully evaluated. If it were to generate unjustifiable conclusions, responsibility for the faulty processing would lie with the programmer, not with the computer. The question of rationality arises only with regard to agents who are sufficiently metacognitive to make deliberate inferences and thus to be responsible for their processing of information.

In summary, Stanovich \& West have provided a valuable picture of individual differences in rationality. Extending this picture will, I think, require greater attention to diversity within individuals, the metacognitive nature of rationality, and the developmental basis for individual differences in metacognition. 
A published commentary on the article:

"Individual differences in reasoning: Implications for the rationality debate?"

by Keith E. Stanovich

Department of Human Development and Applied Psychology, University of Toronto,

Toronto, Ontario, Canada M5S 1V6; kstanovich@oise.utoronto.ca]

and

Richard F. West

School of Psychology, James Madison University, Harrisonburg, VA 22807 westrf@jmu.edu falcon.jmu.edu// westrf

published in BEHAVIORAL AND BRAIN SCIENCES 23 (2000), 645-726.

(c) 2000 Cambridge University Press

Used by permission. 